\title{
Quantifying invasion resistance: the use of recruitment functions to control for propagule pressure
}

\author{
Alice L. Miller, ${ }^{1,7}$ Jeffrem M. Diez,,${ }^{1,2}$ Jon J. Sullivan,,${ }^{1,3}$ Steven R. Wangen,${ }^{1,4}$ Susan K. Wiser,${ }^{5}$ \\ Ross MefFin, ${ }^{1}$ and Richard P. DunCan ${ }^{1,6}$ \\ ${ }^{1}$ BioProtection Research Centre, P.O. Box 84, Lincoln University, Lincoln 7647 New Zealand \\ ${ }^{2}$ Department of Botany and Plant Sciences, University of California, Riverside, California 92521 USA \\ ${ }^{3}$ Department of Ecology, P.O. Box 84, Lincoln University, Lincoln 7647 New Zealand \\ ${ }^{4}$ Wisconsin Institute for Discovery, University of Wisconsin, Madison, Wisconsin 53715 USA \\ ${ }^{5}$ Landcare Research, P.O. Box 40, Lincoln 7640 New Zealand \\ ${ }^{6}$ Institute for Applied Ecology, University of Canberra, Australian Capital Territory 2601 Australia
}

\begin{abstract}
Invasive species distributions tend to be biased towards some habitats compared to others due to the combined effects of habitat-specific resistance to invasion and non-uniform propagule pressure. These two factors may also interact, with habitat resistance varying as a function of propagule supply rate. Recruitment experiments, in which the number of individuals recruiting into a population is measured under different propagule supply rates, can help us understand these interactions and quantify habitat resistance to invasion while controlling for variation in propagule supply rate. Here, we constructed recruitment functions for the invasive herb Hieracium lepidulum by sowing seeds at five different densities into six different habitat types in New Zealand's Southern Alps repeated over two successive years, and monitored seedling recruitment and survival over a four year period. We fitted recruitment functions that allowed us to estimate the total number of safe sites available for plants to occupy, which we used as a measure of invasion resistance, and tested several hypotheses concerning how invasion resistance differed among habitats and over time. We found significant differences in levels of $H$. lepidulum recruitment among habitats, which did not match the species' current distribution in the landscape. Local biotic and abiotic characteristics helped explain some of the between-habitat variation, with vascular plant species richness, vascular plant cover, and light availability, all positively correlated with the number of safe sites for recruitment. Resistance also varied over time however, with cohorts sown in successive years showing different levels of recruitment in some habitats but not others. These results show that recruitment functions can be used to quantify habitat resistance to invasion and to identify potential mechanisms of invasion resistance.
\end{abstract}

Key words: dose-response curve; establishment; habitat invasibility; Hieracium lepidulum; invasive species; New Zealand; safe-site limitation; seed limitation; seed-sowing experiment.

\section{INTRODUCTION}

It is intuitive that habitats differ in their inherent resistance to the establishment and spread of invasive species due to differences in the abundance of resources, natural enemies, mutualists, and competitors (Elton 1958, Rejmánek 1989, Richardson et al. 2000). Quantifying invasion resistance is complicated, however, by the confounding effect of propagule pressure (Williamson 1996, Chytrý et al. 2008, Catford et al. 2012). The probability that an invasive species will establish increases with increasing propagule supply rate (e.g., Ebenhard 1989, Lockwood et al. 2005, Catford et al. 2011). Consequently, two habitats may appear equally prone to invasion but for different reasons; one habitat

Manuscript received 8 April 2013; revised 22 August 2013; accepted 4 September 2013. Corresponding Editor: B. Grewell.

7 Present address: Pyramid Botanical Consultants, 3001 Carriage Drive, Estes Park, Colorado 80517 USA.

E-mail: miller_alice@hotmail.com may have low invasion resistance, with invaders having established under low propagule pressure, while a second may be highly resistant to invasion, but that resistance has been overcome by a high rate of propagule supply. Quantifying invasion resistance and understanding how and why habitats differ in their inherent resistance to invasion thus requires controlling for the confounding effect of propagule pressure (e.g., D'Antonio et al. 2001, Lockwood et al. 2005, Von Holle and Simberloff 2005, Eschtruth and Battles 2009, Catford et al. 2012).

Previous studies have tried to achieve this by analyzing spatial patterns of invasion using multivariate statistical techniques (e.g., Hutchinson and Vankat 1997, Foxcroft et al. 2004, Catford et al. 2011), or using experiments to quantify establishment success in different habitats at a fixed rate of propagule supply (e.g., D'Antonio 1993, Levine 2001, Meekins and McCarthy 2001, Lambrinos 2002). Within a given habitat, however, the establishment response of an invasive species will 
be a nonlinear, typically asymptotic, function of propagule supply rate (D'Antonio et al. 2001, Ruiz and Carlton 2003, Lockwood et al. 2005, Thomsen et al. 2005, Clark et al. 2007, Duncan et al. 2009, Aicher et al. 2011), with the form of this relationship likely to vary among habitats. In North American eastern hemlock forest, for example, differences in the degree to which different habitats were invaded by exotic plants were more apparent at high relative to low propagule supply rates (Eschtruth and Battles 2009). Such interactions between environmental conditions and propagule supply make it difficult to derive a simple measure of invasion resistance that can be used to characterize and compare habitats: The degree to which different habitats are able to resist invasion can vary depending on the rate of propagule supply (Von Holle and Simberloff 2005, Chytrý et al. 2008).

Our aim in this paper was to obtain a clearer understanding of how habitats differ in invasion resistance by focusing on recruitment or dose-response functions; the specific relationship between propagule supply rate and a measure of establishment success (Ruiz and Carlton 2003, Lockwood et al. 2005). For plants, recruitment functions can be quantified from seed addition experiments in which seeds at a range of densities are added to plots and the numbers of recruits recorded (Poulsen et al. 2007, Aicher et al. 2011). Duncan et al. (2009) derived a general equation for the recruitment function based on a mechanistic model describing how the availability of safe sites (sites suitable for seedling establishment sensu Harper et al. 1965) interacts with the number and distribution of seeds landing in a plot to determine recruitment outcomes (see also Aicher et al. 2011). This approach allows us to estimate the total number of safe sites in a plot, which we suggest is a useful measure of invasion resistance that is independent of propagule supply and directly comparable among habitats. Fewer safe sites implies higher invasion resistance because individual propagules arriving at a location have less chance of landing in a safe site and establishing, and at high rates of propagule supply, there will be fewer total recruits.

In this study, we used an extensive seed-sowing field experiment (seeds sown at five densities, in six habitats, in two different years, and monitored for four subsequent years) to construct habitat-specific recruitment functions for Hieracium lepidulum (Strenstr.) Omang (Asteraceae), an invasive plant in the South Island high country of New Zealand. An extensive survey, in which the abundance of $H$. lepidulum was measured in creek margin habitat and at increasing distances into adjacent forest and subalpine habitats in 17 creeks randomly located throughout the study area, showed that $H$. lepidulum is unevenly distributed among habitats, with higher abundance in forest creek margins and treefall gaps relative to intact forest, and higher abundance in these forested habitats than in higher elevation subalpine habitats (tussock grasslands, creek margins, and subalpine scrub; Miller 2006; Miller et al., in press).We used experimentally derived recruitment functions to quantify invasion resistance among habitats, and then assessed whether the current uneven distribution of $H$. lepidulum across habitats reflects this, or whether some habitats are actually less resistant to invasion, but low propagule supply means they have not yet been extensively colonized. We then examined how local abiotic and biotic factors explain variation in invasion resistance among habitats.

\section{Materials And Methods}

\section{Study species}

H. lepidulum (tussock hawkweed) is a broad-leaved, tap rooted rosette-forming perennial herb that is native to Europe. In its native range, $H$. lepidulum is predominately a forest herb, although it may occur in a variety of habitats, except for wetlands and very acidic soils (Wiser and Allen 2000). H. lepidulum is naturalized in the United States and Canada, as well as New Zealand. Since first being recorded as naturalized in New Zealand in 1941, H. lepidulum has steadily increased in frequency and abundance throughout the South Island (Miller 2006). It is now present in a wide range of habitats, from modified montane grassland to beech forest to alpine herb fields, and may dominate invaded communities (Rose et al. 1995, 1998, Duncan et al. 1997, Miller 2006, but see Meffin et al. 2010).

\section{Field site}

This study was carried out in Craigieburn Forest Park, a mountainous landscape managed for recreation and conservation in the mid-Canterbury region of the Southern Alps, New Zealand $\left(43^{\circ} 10^{\prime} \mathrm{S}, 172^{\circ} 45^{\prime} \mathrm{E}\right.$; see Appendix: Fig. A1). The park ranges from $800 \mathrm{~m}$ to $2000 \mathrm{~m}$ elevation, with a mean annual temperature of $8.2^{\circ} \mathrm{C}$ and mean annual precipitation of $1533 \mathrm{~mm}$ (MetStation Landcare Research, Lincoln, New Zealand, unpublished data). Soils are recent or high-country yellow brown earths (Anonymous 1968). Mountain beech forest (Nothofagus solandri var. cliffortiodes) dominates from $\sim 650 \mathrm{~m}$ to $1400 \mathrm{~m}$ elevation, and gives way to subalpine scrub, tussock grasslands (grasslands dominated by long-lived, bunch-forming Chionochloa spp.), and alpine herbfields at higher elevations.

\section{Experimental design}

Seed density manipulation.-We used seven seed density treatments to construct recruitment functions: control with no seed addition and no initial wetting, procedural control with no seed addition but with wetting, and seed addition at rates of 25, 125, 625, 3125, and 15625 seeds per $30 \times 30 \mathrm{~cm}$ plot with wetting (or $278,1389,6944,34722$, and 173611 seeds $/ \mathrm{m}^{2}$ ). Wetting was used to prevent the seeds from blowing away during seed addition. The study area has a long history of $H$. lepidulum invasion (Wiser et al. 1998), and so seeds were sown into previously invaded habitats, although $H$. 
lepidulum is patchily distributed throughout the study area and often occurs at low abundance. To minimize natural seed dispersal into plots, any $H$. lepidulum plants naturally occurring in or within $20 \mathrm{~m}$ of the experimental plots were removed prior to seed addition. Control treatment plots rarely had seedlings establish (mean of 0.1 seedlings/plot across all control treatments, 14-fold less than the lowest seed addition rate) and were not included in the analysis where we consider only the five seed density treatments with seed added. The seed addition levels were chosen to encompass the levels of natural seed rain estimated to occur given the range in fecundity and density of $H$. lepidulum plants in the study area (Miller 2006), and to include sufficiently high densities to try and saturate available safe sites. Seed was collected in the field immediately prior to sowing from the lower reaches of catchments in the Black Range, close to the experimental study area (Appendix: Fig. A1). Initial seed viability (determined by placing five replicates of 50 seeds on moist filter paper in petri dishes and recording subsequent germination) was $85 \%$ (A. L. Miller, unpublished data). The long-term persistence of $H$. lepidulum seed in the soil is unknown, but a seed burial experiment carried out as part of this study revealed that $33 \%$ of seeds remained viable in the soil after 12 months (A. L. Miller, unpublished data).

Experimental layout.-To determine how the form of the recruitment function varied among habitats, the seed density treatments were applied to each of six major habitat types in the study area: forest creek margin, forest interior, forest treefall gap, subalpine creek margin, subalpine tussock grassland, and subalpine scrub. Because yearly environmental variation can affect patterns of establishment, the generality of the results were tested by repeating the seed-sowing experiment in two consecutive years (termed cohort 1 and cohort 2), both using the same randomized block design with six replicate blocks in each of the six habitat types. The cohort 2 blocks were located adjacent to the cohort 1 blocks: The low establishment in control plots indicates that there was little or no seed contamination of cohort 2 plots by cohort 1 .

For forest and subalpine creek margin habitat, blocks were located a random distance up Craigieburn Stream, with the forest creek blocks below treeline and the subalpine creek blocks in a basin above treeline. For forest interior and subalpine tussock habitat, blocks were located a random distance up Craigieburn Stream and a random distance into the adjacent habitat, with the latter distance at least $20 \mathrm{~m}$ (to avoid the influence of the creek margin) and no more than $200 \mathrm{~m}$ (for logistical reasons). Blocks in forest treefall gaps were located in the nearest gap $>25 \mathrm{~m}^{2}$ a random distance up the creek and a random distance into the forest, as for forest and subalpine creek habitats. Subalpine scrub blocks were selected by mapping all subalpine scrub patches within the study catchment, and then randomly selecting six of these patches.
Each block comprised three replicate plots $(30 \times 30$ $\mathrm{cm}$ ) of each of the seven seed density treatments, randomly positioned in a $16-\mathrm{m}^{2}$ area with at least a $30-\mathrm{cm}$ buffer between each plot. Seed density treatments were randomly assigned to each plot following plot placement. Plots were permanently marked with two labeled corner pegs for relocation. The first cohort was sown in March 2003, and the second cohort in March 2004 (autumn).

We measured environmental factors that might explain differences in invasion resistance among habitats. On each plot we measured light (percentage of photosynthetic photon flux density [PPFD]), ground cover (vascular plants, bryophyte, litter, bare ground, and rock recorded using a modified Braun-Blanquet cover scale: $1,0-1 \% ; 2,2-5 \% ; 3,6-25 \% ; 4,26-50 \% ; 5$, 51-75\%; and 6, 76-100\% [Hurst and Allen 2007]), and recorded all vascular plant species present.

Light was measured using percentage of PPFD under overcast skies. Fifteen instantaneous light measurements $\left(Q_{i}\right)$ were taken at $1 \mathrm{~cm}$ above ground level over the center of each plot using point quantum sensors (LI190SA, LICOR, Lincoln, Nebraska, USA). Outside (i.e., open) light conditions $\left(Q_{\mathrm{o}}\right)$ were logged continuously throughout the measurement period using two quantum sensors linked to a datalogger (LI-1400, LICOR) that recorded one-minute averages. Light conditions within each plot (\%PPFD) were then calculated as $Q_{i} / Q_{\mathrm{o}} \times 100$.

On each block, we measured soil fertility and moisture content by taking four soil samples, one from each corner, using a $10-\mathrm{cm}$ soil corer. The four samples from each block were bulked, air-dried, sieved, and analyzed for $\mathrm{pH}$, calcium, Olsen-soluble phosphorous, base saturation (\%), total carbon and total nitrogen, and moisture content using gravimetric analysis. The first axis of a principle components analysis of these soil variables was used in analyses. This axis, referred to as soil fertility hereafter, explained $51 \%$ of the variation in the soil variables and had the following loadings: percentage of base saturation (0.54), calcium (0.49), $\mathrm{pH}(0.43)$, nitrogen $(0.38)$, soil moisture $(-0.08)$, Olsensoluble phosphorous $(0.15)$, and $\mathrm{C}: \mathrm{N}$ ratio $(-0.33)$.

Plant recruitment.-To quantify recruitment as a response to seed-sowing density, the number of $H$. lepidulum plants present per plot was censused at intervals after seed sowing for four years (to March 2007 for cohort 1 and March 2008 for cohort 2; see Appendix: Fig A2). For plots with very high seedling densities, a quadrat divided into a $1 \times 1 \mathrm{~cm}$ grid was used, and $201-\mathrm{cm}^{2}$ cells were randomly selected for counting, with that count scaled up to the total plot area. We did not tag and follow individual seedlings. In the second year following sowing, some new seedlings were observed in plots, possibly reflecting delayed germination of sown seeds. By year four, few of the plants had reached reproductive maturity and there was little evidence of new seedling germination, so the plants counted in year four derive primarily from the seed 
originally sown into the plots rather than subsequent recruitment.

\section{Statistical methods}

We used the general recruitment function described in Duncan et al. (2009) to quantify the relationship between the number of seeds added and the number of $H$. lepidulum plants that recruited. This general recruitment function takes the following form:

$$
r=b n\left[1-\frac{\lambda^{\lambda}}{(\lambda+s / n)^{\lambda}}\right]
$$

where $r$ is the number of plants counted in plots with $s$ seeds sown. The remaining parameters are estimated from the data and have biological interpretations: $n$ is the number of sites capable of supporting a single plant, $b$ is the proportion of those sites that are safe sites in which plants can persist, and $\lambda$ can be interpreted as the degree of size heterogeneity among safe sites (size heterogeneity refers to variation in the size of sites that are capable of supporting a single seedling; see Duncan et al. 2009). This recruitment function has an asymptote at the total number of safe sites, $b n$, which occurs when all safe sites are occupied.

We fitted recruitment functions using a hierarchical Bayesian framework in order to account for nonindependence due to the nested experimental design (plots were nested within blocks and habitats). Specifically, we modeled the number of recruits using a negative binomial distribution with a variance estimated from the data and a mean described by the recruitment function. The parameter describing the proportion of safe sites, $b$, was constrained to values between 0 and 1 using the logit link function, and parameters $n$ and $\lambda$ were constrained to be positive with log links. To account for the nested design, each of these three parameters at the plot level was then modeled as nested within treatments, blocks, and habitats.

We fitted separate models to quantify recruitment functions for each cohort in each habitat in each of the four years after seed sowing so that we could examine how invasion resistance varied at different stages in the establishment process (e.g., from initial germination through subsequent cohort development).

All parameters were assigned noninformative prior distributions. Models were fitted using OpenBugs v2.10 (Thomas et al. 2006) called using the BRugs package from R 2.9 (R Core Development Team 2008) and run for between 40000 and 60000 iterations with burn-in periods of 10000-15000 and moderate thin rates (typically 10) to achieve convergence. Convergence was monitored using the Gelman-Rubin statistic and inspection of sample histories.

We tested whether the parameters of the fitted recruitment functions differed among cohorts and habitats within the Markov chain Monte Carlo (MCMC) model-fitting procedure. Specifically, the probability that habitats differed was calculated by subtracting the lowest habitat value from the highest habitat value for each parameter, and finding the cumulative probability that the posterior distribution of this difference was greater than zero. The hypothesis that resistance varies among cohorts was tested by subtracting the value of each parameter in cohort 2 from cohort 1 , in each habitat, and finding the cumulative probabilities that the differences were greater than zero.

We used the asymptote of the recruitment function, given by $b n$, as a measure of habitat susceptibility to invasion independent of propagule pressure (habitat susceptibility being the inverse of habitat resistance). Thus, $b n$ is the expected number of plants present assuming seed saturation, or the total number of safe sites available for plants to occupy per plot at a given time. This measure of habitat susceptibility has two components: $n$, the number of sites, and $b$, the proportion of sites that are safe for establishment and persistence. Habitats could have lower resistance to invasion (higher $b n$ ) because the area required to support a single plant is smaller, meaning there are more sites available, and/or because a greater proportion of those sites are safe for establishment and persistence. These values change through time, however, as a given plot can support progressively fewer, larger individuals as the cohort ages (Duncan et al. 2009).

To identify factors that might confer resistance to invasion, we conducted a multiple regression with estimated values of $b n$ as the response variable and habitat (as a factor) and each of four continuous covariates (light, species richness, percent vascular plant cover, and the first axis of the soil fertility principal component analysis [PCA]) as independent variables. This analysis was carried out at the block level, which was the lowest level in the nested study design at which we could quantify recruitment curves and obtain estimates of $b n$. Separate regressions were run for each cohort and also for the average $b n$ of both cohorts. Stepwise variable selection based on AIC was used to determine the importance of these variables.

\section{RESUlts}

The number of $H$. lepidulum plants four years after seed sowing generally increased with greater numbers of seeds sown for both cohorts across all habitats (Fig. 1). Although the mean number of plants in all plots was similar across habitats for cohort 2, there were clear differences among habitats for cohort 1 , with subalpine tussock and creek habitats, in particular, having higher rates of recruitment. The mean number of plants from experimental sowings within each habitat did not coincide with the average abundance of plants in those habitats from field survey data (Fig. 1). Relative to other habitats, subalpine tussock, subalpine creek, and forest interior habitats had low densities of $H$. lepidulum in the field survey, but comparable or higher than average numbers of plants in the experimentally sown plots. 


\section{Cohort 1}

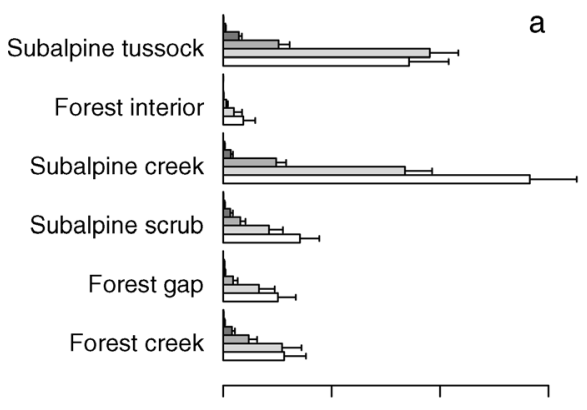

b

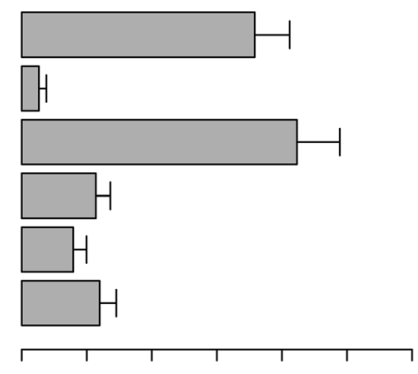

C

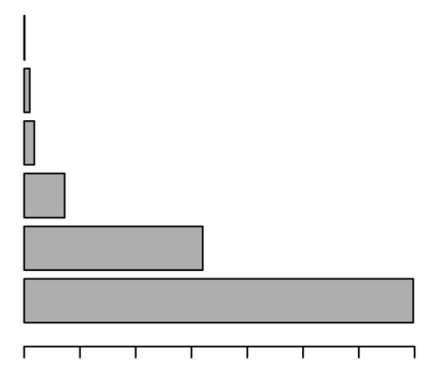

Cohort 2
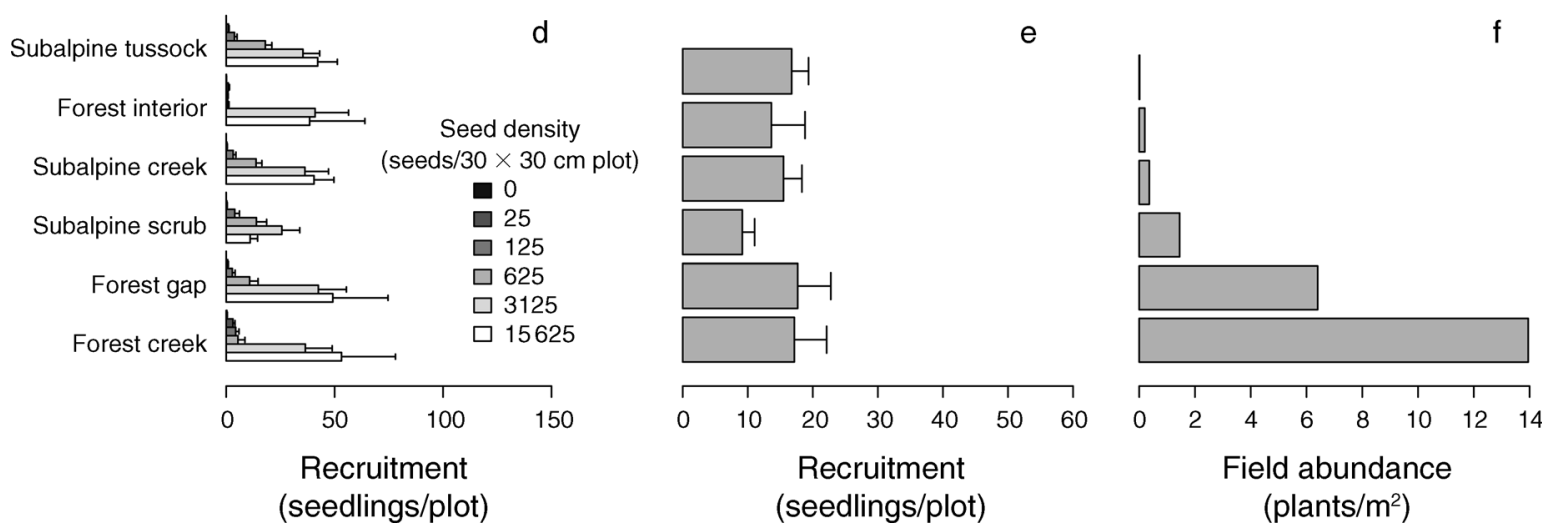

FIG. 1. Recruitment of Hieracium lepidulum plants four years after experimental seed addition at five different densities into six different habitat types in New Zealand's Southern Alps for cohorts 1 and 2, showing (a,d) the number of plants recruited as a function of seed-sowing density in the six habitats and (b,e) the overall mean number of plants per plot in the six habitats. For comparison (c, f) show the observed mean abundance of $H$. lepidulum in the six habitats from the field survey data. Cohort 1 was sown in March 2003, and cohort 2 in March 2004.

The number of plants that recruited was a function of both seed-sowing density and habitat, with the form of the recruitment function differing among habitats (Fig. 2, Table 1, Appendix: Table A1). Subalpine tussock and subalpine creek habitats had high rates of recruitment at all seed densities only in cohort 1 , but otherwise, the ranking of recruitment among habitats was similar between cohorts. All recruitment curves appear to approach their upper asymptote at the highest seed densities, implying saturation of safe sites.

The ranking of habitats by the total number of safe sites per plot $(b n)$ after four years suggests that, for both cohorts, forest interior habitat was the most resistant, while subalpine tussock and subalpine creek habitats were the least resistant to invasion (Fig. 2, Table 1). Overall, the ranking of habitats in the two cohorts was similar, although estimates of the total number of safe sites differed. However, recruitment curves for the same habitat changed through time, converging on their ranking after four years in different ways (Appendix: Fig. A2). For example, for cohort 1 in year 1, the intact forest habitat had the greatest number of safe sites, reflecting high rates of germination and initial establishment. Rates of seedling mortality in the intact forest were high, however, so that by year 3 it was evident that there were few sites in intact forest plots suitable for long-term persistence, and the total number of safe sites had declined to below those of other habitats. Subalpine scrub habitat, in contrast, had relatively low numbers of safe sites, but then low rates of seedling mortality (Appendix: Fig. A2).

There were significant differences among habitats in the parameters of the recruitment function after four years for both cohorts 1 and 2, but no strong evidence that, within habitats, the two cohorts differed (Appendix: Table A1). Forest interior and forest gap habitats tended to have many sites, but only a small proportion of those were safe, whereas forest creek and subalpine scrub habitats had fewer sites, but a greater proportion of these were safe sites, and subalpine tussock and subalpine creek habitats had intermediate to high values of both (Fig. 2).

The effects of covariates on $b n$, the measure of habitat invasion susceptibility, varied between cohorts. For cohort 1, three covariates (light, vascular plant cover, and species richness) were positively correlated with $b n$ when analyzed in univariate regressions, and there were also apparent differences among habitats (Fig. 3). Plots 


\section{Cohort 1}
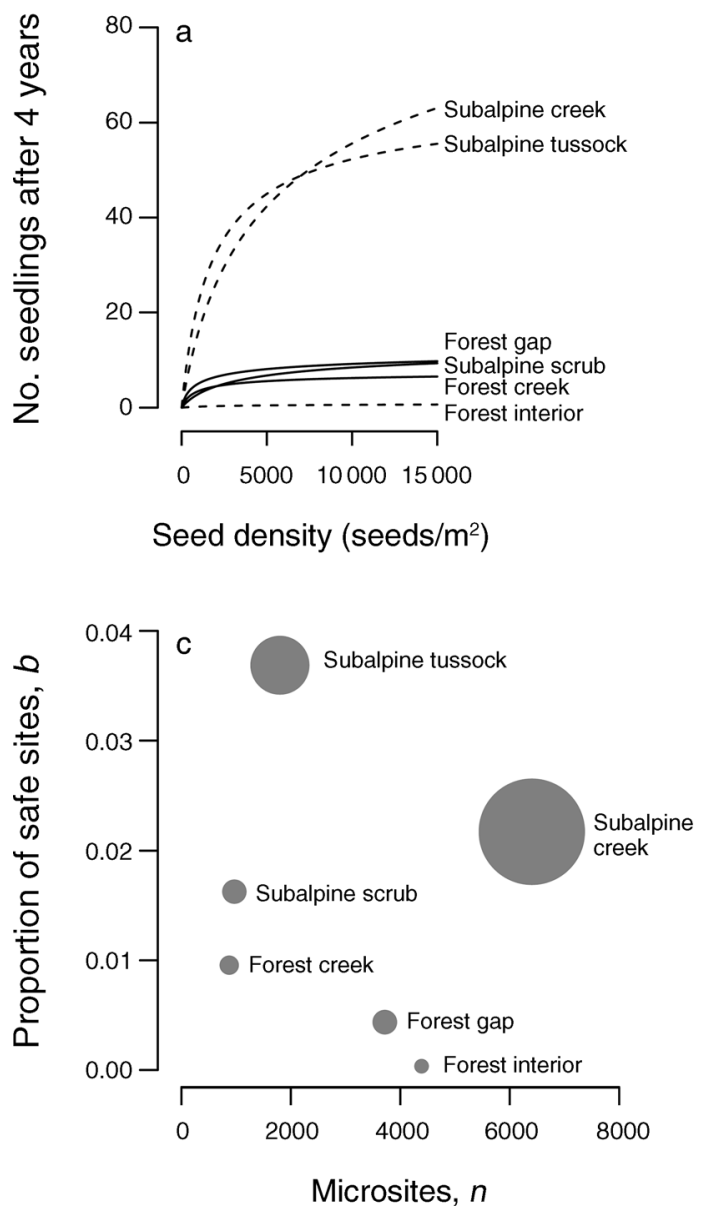

Cohort 2
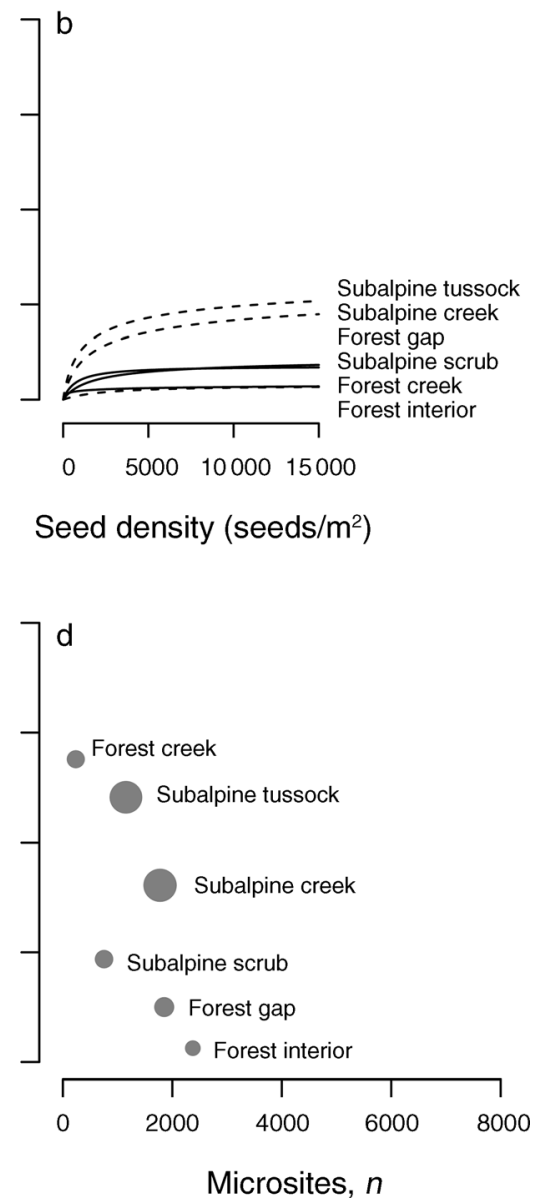

FIG. 2. (a, b) Fitted recruitment curves showing the number of seedlings recruited after four years as a function of seed-sowing density for three forest habitats (solid lines) and three subalpine habitats (dashed lines), for cohort 1 and 2. (c, d) The six habitats plotted with respect to the parameters $n$ (the number of microsites) and $b$ (the proportion of safe sites) from the fitted recruitment functions for cohorts 1 and 2. The size of the circles is proportional to the product $b n$, a measure of habitat resistance to invasion (larger circles indicate lower invasion resistance).

in subalpine tussock and subalpine creek habitat where invasion resistance was low, for example, tended to have high light, high vascular plant cover, and high species richness. Using multiple regression to control for differences among habitats and for the influence of the other covariates, the same three variables were retained by stepwise Akaike information criterion (AIC) variable selection, along with habitat (as a factor). However, of the continuous variables, only species richness had a coefficient significantly different from zero $(\beta=2.78, P$ $<0.01)$. The effects of light $(\beta=-0.89, P=0.10)$ and percent cover $(\beta=-0.71, P=0.13)$ were both trending negative once habitat was accounted for, but were not significantly different from zero. Negative relationships would suggest that areas with higher light and vascular plant cover were more resistant to invasion once accounting for species richness and additional habitatspecific differences. There were no significant relationships for cohort 2 (no variables retained by stepwise AIC and all $P>0.1$ ). When averaging the two cohorts, results were similar to cohort 1 alone, except that percent cover was not retained in the final model.

\section{Discussion}

Quantifying invasibility remains an elusive goal in invasion ecology (Catford et al. 2012), yet managing biological invasions requires an understanding of how habitats or locations differ in their inherent resistance to invasion (Hobbs and Humphries 1995, Catford et al. 2012). Recruitment functions allow us to understand how propagule supply rates influence rates of plant recruitment (Poulsen et al. 2007, Duncan et al. 2009, Aicher et al. 2011) and to quantify how this relationship differs among habitats. The asymptote of the recruitment function defines the number of safe sites available for colonization: Fewer safe sites implies higher invasion resistance because individual propagules arriving at a location have less chance of landing in a safe site and 
TABLE 1. Habitat-specific recruitment function parameters, number of flowers and percentage of plots with flowering plants, and mean light, vascular cover, species richness, and soil fertility values.

\begin{tabular}{|c|c|c|c|c|c|c|c|c|c|c|}
\hline Habitat & $b$ & $n$ & $\lambda$ & $b n$ & $\begin{array}{l}\text { No. } \\
\text { flowers }\end{array}$ & $\begin{array}{c}\text { Flowering } \\
(\%)\end{array}$ & $\begin{array}{c}\text { Light } \\
(\% \text { PPFD) }\end{array}$ & $\begin{array}{l}\text { Vascular } \\
\text { cover }\end{array}$ & $\begin{array}{l}\text { Species } \\
\text { richness }\end{array}$ & Soil fertility \\
\hline \multicolumn{11}{|l|}{ Cohort 1} \\
\hline Forest creek & 0.0096 & 875 & 0.41 & 28.70 & 18 & 0.014 & $10.6(7.8)$ & $3.4(1.2)$ & $14.0(10.5)$ & $0.04(1.66)$ \\
\hline Forest interior & 0.0004 & 4390 & 0.18 & 11.36 & 2 & 0.007 & $3.7(2.2)$ & $1.6(1.1)$ & $2.3(1)$ & $-2.0(0.52)$ \\
\hline Forest gap & 0.0044 & 3719 & 0.33 & 28.70 & 46 & 0.054 & $8.5(4.9)$ & $2.7(1.4)$ & $7.0(4.8)$ & $-0.61(0.69)$ \\
\hline Subalpine creek & 0.0217 & 6403 & 0.26 & 228.70 & 0 & 0 & 60.8 (18.3) & $5.4(0.8)$ & $36.7(13.4)$ & $0.54(0.82)$ \\
\hline Subalpine scrub & 0.0163 & 969 & 0.23 & 29.74 & 311 & 0.253 & $24.9(17.7)$ & $5.1(0.9)$ & $16.2(5.4)$ & $2.36(2.15)$ \\
\hline Subalpine tussock & 0.0369 & 1802 & 0.71 & 97.08 & 0 & 0 & $49.8(14.7)$ & $4.6(0.9)$ & $21.5(9.6)$ & $-0.33(0.62)$ \\
\hline \multicolumn{11}{|l|}{ Cohort 2} \\
\hline Forest creek & 0.0276 & 237 & 0.08 & 42.75 & 72 & 0.039 & $8(3.1)$ & $3.5(1.5)$ & & \\
\hline Forest interior & 0.0013 & 2373 & 1.16 & 35.98 & 2 & 0.001 & $4.3(1.7)$ & $1.4(1.2)$ & & \\
\hline Forest gap & 0.0050 & 1853 & 0.57 & 55.58 & 24 & 0.013 & $39.79(25.3)$ & $3.0(1.2)$ & & \\
\hline Subalpine creek & 0.0161 & 1776 & 0.29 & 46.86 & 4 & 0.002 & 73.9 (18) & $5.7(0.6)$ & & \\
\hline Subalpine scrub & 0.0094 & 751 & 1.12 & 19.19 & 7 & 0.007 & $24.9(28.7)$ & $5.6(0.6)$ & & \\
\hline
\end{tabular}

Notes: The modes of parameters $b, n$, and $\lambda$ are given, and the means of covariates are shown with standard deviations in parentheses. Parameters are: $n$ is the number of sites capable of supporting a single plant, $b$ is the proportion of those sites that are safe sites in which plants can persist, and $\lambda$ can be interpreted as the degree of size heterogeneity among safe sites (size heterogeneity refers to variation in the size of sites that are capable of supporting a single seedling). Numbers of flowers and percentage of plots that had flowering plants are from year 4. Light was measured as the percentage of photosynthetic photon flux density (PPFD). Vascular cover was based on a modified Braun-Blanquet cover scale: 1, 0-1\%;2, 2-5\%;3, 6-25\%; 4, 26-50\%; 5, 51-75\%; and 6, 76$100 \%$. Species richness and soil fertility data was collected only for cohort 1 and is based on data from six blocks/habitat. Species richness was measured as the number of species per $30 \times 30 \mathrm{~cm}$ plot. Soil fertility is the first PCA axis, with loadings as described in the Methods.
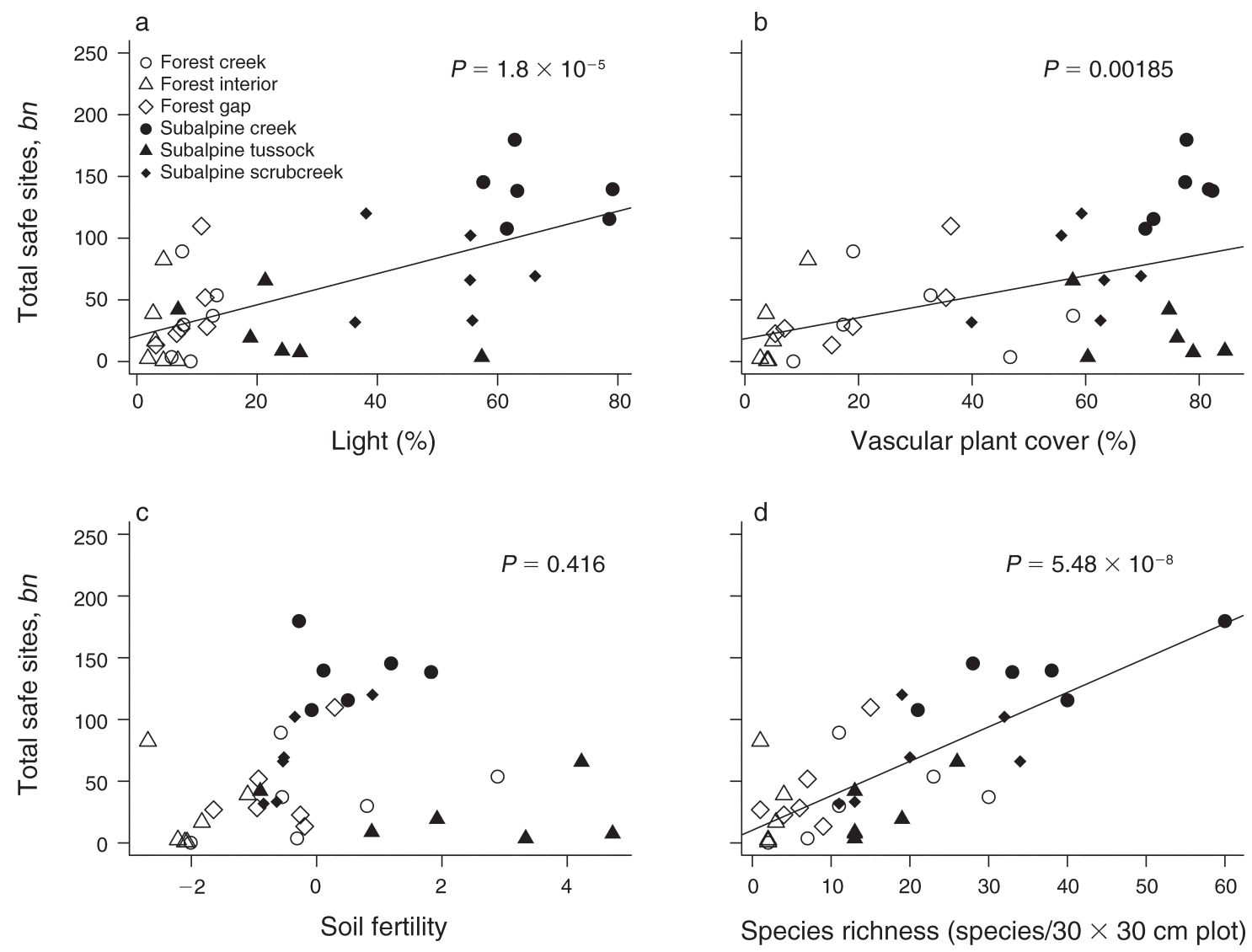

FIG. 3. Relationships between covariates (percentage of light, percent vascular cover, soil fertility, and species richness) and a measure of invasion resistance, $b n$ (the total number of safe sites). Solid symbols are subalpine habitats, and empty symbols are forest habitats. Soil fertility is the first axis of a PCA, and includes percentage of base saturation, calcium, $\mathrm{pH}$, nitrogen, soil moisture, Olsen-soluble phosphorous, and C:N ratio. The $P$ values are from univariate regressions. 
establishing, and because fewer safe sites restricts the total number of recruits at high rates of propagule supply. Hence, this estimate of the number of safe sites provides a quantitative measure of invasion resistance independent of propagule supply rate. Despite their utility, quantitative recruitment (or dose-response) data for invasive species are rare (Ruiz and Carlton 2003, Lockwood et al. 2005). In this study, the recruitment functions derived from an extensive seed-sowing experiment provided a unique picture of the potential for an invasive species to establish in different habitats, highlighting the role of habitat resistance in determining invasion outcomes.

\section{Species distribution-invasion resistance mismatch}

There was a lack of correspondence between the current spatial distribution of $H$. lepidulum in the study area and our estimates of invasion resistance by habitat. The currently low densities of H. lepidulum in subalpine habitats, particularly in tussock grassland and creek margins, does not appear due to the ability of these habitats to resist invasion, implying it is most likely due to low propagule supply rates. Below treeline, estimates of invasion resistance were more closely matched to field abundances: The forest interior was highly resistant to invasion and had a low density of $H$. lepidulum, while forest creek margin and forest treefall gaps were less resistant to invasion and had correspondingly higher densities. These outcomes are consistent with the following invasion scenario: $H$. lepidulum is abundant in grassland habitats at lower elevations in the study region that have resulted from forest clearance in the valley bottoms; it is currently spreading from these lower elevation sites through upland forest and into subalpine areas, but has yet to fully colonize the higher reaches; consequently, current densities of $H$. lepidulum in subalpine areas are below carrying capacity for those habitats due to a lack of propagules reaching higher elevation sites. While the intact forest interior appears relatively resistant to invasion by $H$. lepidulum, spread through forested areas is likely facilitated by the presence of open creeks and treefall gaps, which are much less invasion resistant. Spence et al. (2011b) similarly found that the probability of $H$. lepidulum invasion in New Zealand mountain beech forest was high following canopy disturbance. Projected levels of $H$. lepidulum in intact forest were driven by persistence of individuals already established, and from propagule supply from creek margins and forest edges (Spence et al. 2011b). The clear implication is that the density of $H$. lepidulum is likely to increase in subalpine habitats as the population continues to expand and the rate at which propagules reach sites above treeline increases. We expect these subalpine areas to be more rapidly colonized in catchments with a greater proportion of open forest, creek margin, or treefall gap habitat that should facilitate spread.
Mechanisms underlying differences in invasion resistance

Changes in recruitment patterns through time highlight the mechanisms underlying differences in invasion resistance among habitats. In forest interior habitat, seedling abundance after four years was the result of high seedling mortality from initially high seedling emergence, while in subalpine tussock and subalpine creek habitats, final seedling abundance resulted from a lower rate of emergence, but lower rates of seedling mortality. In subalpine scrub habitats, final abundance reflected low initial emergence, followed by moderate seedling mortality (see Appendix: Fig. A2). These patterns were, in turn, linked to differences among habitats in the parameters of the recruitment function describing the number of microsites $(n)$ and the proportion of sites that are safe $(b)$. Forest interior habitats, with initially high seedling emergence, had a large number of microsites, but by year 4 , high mortality resulted in relatively few safe sites that allowed persistence (Fig. 2). Subalpine tussock grasslands, in contrast, had fewer microsites, but a greater proportion of these were safe sites (Fig. 2), linked to the pattern of low initial emergence and lower rates of seedling mortality (see Appendix: Fig. A2).

The positive correlation between the number of safe sites $(b n)$ and light, vascular cover, and species richness, suggest that high values of these factors are associated with lower invasion resistance (Fig. 3). Nevertheless, species richness was the variable most strongly associated with invasion resistance and the only variable that retained a significant relationship in multiple regression. Hence, both within- and among-habitats more speciesrich sites had lower invasion resistance. Wiser et al. (1998) similarly found a strong relationship between species richness and $H$. lepidulum invasion in forests surrounding the study area over a 23-year period. One explanation for this relationship is that $H$. lepidulum performs well at sites where other species do well because the underlying conditions at those sites favor plant establishment, survival, and growth (Levine and D’Antonio 1999, Stachowicz and Byrnes 2006). However, species richness had a stronger relationship with invasion resistance than measures of resource availability such as soil fertility and light in both this study and Wiser et al. (1998), which suggests either both studies failed to measure one or more key resources, or that an alternative explanation underlies the relationship. One alternative is that increased spatial heterogeneity associated with greater species richness provides a greater number of safe sites for $H$. lepidulum establishment and survival (Tilman 1997, Wiser et al. 1998, Smith et al. 2004). Another is that higher plant species richness is accompanied by an increased diversity and abundance of beneficial belowground organisms (e.g., Kowalchuk et al. 2002, Eisenhauer et al. 2010, Spence et al. 2011a), which could enhance establishment independent of underlying fertility (van der Heijden et al. 2008). 


\section{Implications for invasibility and species spread}

The variation in invasion resistance among habitats implies that the pattern of spread and final distribution of $H$. lepidulum across the landscape will not be uniform. In addition to this underlying spatial variation, this study highlights two ways in which temporal variation will likely influence species' spread. First, the two cohorts differed in their recruitment patterns. While initial recruitment was lower in the first cohort compared to the second, the final seedling numbers were higher in subalpine creek and tussock grassland habitats. These differences most likely reflect annual climatic variations. Relative to cohort 1, for example, cohort 2 experienced a warmer spring and summer following seed sowing (Craigieburn Climate Station Data, Lincoln, New Zealand, unpublished data), which may explain cohort 2's higher initial germination rates and higher subsequent summer mortality. While the final ranking of invasion resistance among habitats was similar for the two cohorts, they arrived at those rankings via different pathways over the four years, pointing to annual environmental variability as a factor influencing invasion resistance with potential to result in variable outcomes across habitats.

Second, while a seed-sowing experiment followed for four years constitutes a relatively long-term ecological study, the capacity of habitats to support $H$. lepidulum populations and for these to contribute to subsequent spread of the species depends on plant performance over longer time scales. For example, while seedling recruitment was high in the less invaded subalpine habitats (tussock grassland and creek margins), fewer of these plants had reached reproductive maturity at the end of the four-year study, compared with plants established in forest creek margin, forest gap, and subalpine scrub habitats (Table 1). There are then at least two scenarios for longer term dynamics in these subalpine habitats: Conditions may be unsuitable for the transition of seedlings into reproductive adults and, despite high seedling recruitment, the habitats may therefore act as population sinks. Alternatively, the dynamics may simply be slower than in forest creek margin, forest gap, and subalpine scrub habitats, but will eventually result in high densities of reproductive plants. These differences among habitats stress the importance of considering the whole life cycle, through recruitment, survival, and reproduction, for ultimately assessing invasibility and habitat resistance. While our measure of invasion resistance $(b n)$ provides a habitat-specific estimate of the number of individuals of a given age that a site can support, the rate at which those individuals attain reproductive maturity and their subsequent reproductive output will determine the potential for population increase. Conversely, although relatively high numbers of plants established in subalpine creek habitats very few reached reproductive maturity after four years (Table 1). Demographic models derived from longer term data could be used to develop more refined measures of invasion resistance.

\section{ACKNOWLEDGMents}

We thank the E. L. Hellaby Indigenous Grasslands Research Trust for funding this study and the Department of Conservation for permission to use the study area. We are grateful to Marcus Bridge, Susan Thornton, Melinda Goudie, Mary Hutchinson, Sean Bithell, Laura Spence, and Sean Fergus for field assistance.

\section{Literature Cited}

Aicher, R. J., L. Larios, and K. N. Suding. 2011. Seed supply, recruitment, and assembly: quantifying relative seed and establishment limitation in a plant community context. American Naturalist 178:464-477.

Anonymous. 1968. Soils of New Zealand, Part I. New Zealand Department of Scientific and Industrial Research, Wellington, New Zealand.

Catford, J. A., P. A. Vesk, D. M. Richardson, and P. Pyšek. 2012. Quantifying levels of biological invasion: towards the objective classification of invaded and invasible ecosystems. Global Change Biology 18:44-62.

Catford, J. A., P. A. Vesk, M. D. White, and B. A. Wintle. 2011. Hotspots of plant invasion predicted by propagule pressure and ecosystem characteristics. Diversity and Distributions 17:1099-1110.

Chytrý, M., V. Jarošík, P. Pyšek, O. Hájek, I. Knollová, L. Tichý, and J. Danihelka. 2008. Separating habitat invasibility by alien plants from the actual level of invasion. Ecology 89: $1541-1553$.

Clark, C. J., J. R. Poulsen, D. J. Levey, and C. W. Osenberg. 2007. Are plant populations seed limited? A critique and meta-analysis of seed additiion experiments. American Naturalist 170:128-142.

D’Antonio, C. M. 1993. Mechanisms controlling the invasion of coastal plant communities by the alien succulent Carpodetus edulis. Ecology 74:83-95.

D'Antonio, C., J. Levine, and M. Thomson. 2001. Ecosystem resistance to invasion and the role of propagule supply: a California perspective. Journal of Mediterranean Ecology 2: 223-245.

Duncan, R. P., K. M. Colhoun, and B. D. Foran. 1997. The distribution and abundance of Hieracium species (Hawkweeds) in the dry grasslands of Canterbury and Otago. New Zealand Journal of Ecology 21:51-62.

Duncan, R. P., J. M. Diez, J. J. Sullivan, S. Wangen, and A. L. Miller. 2009. Safe sites, seed supply, and the recruitment function in plant populations. Ecology 90:2129-2138.

Ebenhard, T. 1989. Bank vole [Clethrionomys glareolus (Schreber, 1780)] propagules of different sizes and island colonization. Journal of Biogeography 16:173-180.

Eisenhauer, N., et al. 2010. Plant diversity effects on soil microorganisms support the singular hypothesis. Ecology 91: 485-496.

Elton, C. S. 1958. The ecology of invasions by animals and plants. Methuen, London, UK.

Eschtruth, A. K., and J. J. Battles. 2009. Assessing the relative importance of disturbance, herbivory, diversity, and propagule pressure in exotic plant invasions. Ecological Monographs 79:265-280.

Foxcroft, L. C., M. Rouget, D. M. Richardson, and S. MacFayden. 2004. Reconstructing 50 years of Opuntia stricta invasion in the Kruger National Park, South Africa: environmental determinants and propagule pressure. Diversity and Distributions 10:427-437.

Harper, J., J. Williams, and G. Sagar. 1965. The behaviour of seeds in soil: I. The heterogeneity of soil surfaces and its role in determining the establishment of plants from seed. Journal of Ecology 53:273-286. 
Hobbs, R. J., and S. E. Humphries. 1995. An integrated approach of the ecology and management of plant invasions. Conservation Biology 9:761-770.

Hurst, J. M., and R. B. Allen. 2007. The Recce method for describing New Zealand vegetation: field protocols. Landcare Research, Lincoln, New Zealand.

Hutchinson, T. F., and J. L. Vankat. 1997. Invasibility and effects of Amur Honeysuckle in southwestern Ohio Forests. Conservation Biology 11:1117-1124.

Kowalchuk, G. A., D. S. Buma, W. d. Boer, P. G. L. Klinkhamer, and J. A. v. Veen. 2002. Effects of aboveground plant species composition and diversity on the diversity of soil-borne microorganisms. Antonie van Leeuwenhoek 81:509-520.

Lambrinos, J. G. 2002. The variable invasive success of Cortaderia species in a complex landscape. Ecology 83:518529.

Levine, J. M. 2001. Local interactions, dispersal, and native and exotic plant diversity along a California stream. Oikos 95: 397-408.

Levine, J. M., and C. M. D'Antonio. 1999. Elton revisited: a review of evidence linking diversity and invasibility. Oikos 87:15-26.

Lockwood, J. L., P. Cassey, and T. M. Blackburn. 2005. The role of propagule pressure in explaining species invasion. Trends in Ecology and Evolution 20:223-228.

Meekins, J. F., and B. C. McCarthy. 2001. Effect of environmental variation on the invasive success of a nonindigenous forest herb. Ecological Applications 11: 1336-1348.

Meffin, R., A. Miller, P. Hulme, and R. Duncan. 2010. Experimental introduction of the alien weed Hieracium lepidulum reveals no significant impact on subalpine plant communities in New Zealand. Diversity and Distributions 16:804-815.

Miller, A. L. 2006. Untangling spatial distribution patterns of the invasive herb Hieracium lepidulum Stenstr. (Asteraceae) in a New Zealand mountain landscape. Dissertation. Lincoln University, Lincoln, New Zealand.

Miller, A. L., S. K. Wiser, J. J. Sullivan, and R. P. Duncan. In press. Creek habitats as sources for the spread of an invasive herb in a New Zealand mountain landscape. New Zealand Journal of Ecology.

Poulsen, J. R., C. W. Osenberg, C. J. Clark, D. J. Levey, and B. M. Bolker. 2007. Plants as reef fish: Fitting the functional form of seedling recruitment. American Naturalist 170:167183.

R Development Core Team. 2008. R: A language and environment for statistical computing. R Foundation for Statistical Computing, Vienna, Austria.

Rejmánek, M. 1989. Invasibility of plant communities. Pages 369-388 in F. d. Castri. R. H. Groves, F. J. Kruger, M. Rejmánek, and M. Williamson, editors. Biological invasions: a global perspective. John Wiley and Sons, New York, New York, USA.
Richardson, D. M., N. Allsopp, C. M. D’Antonio, S. J. Milton, and M. Rejmánek. 2000. Plant invasions: the role of mutualisms. Biological Reviews 75:65-93.

Rose, A. B., L. R. Basher, S. K. Wiser, K. H. Platt, and I. H. Lynn. 1998. Factors predisposing short-tussock grasslands to Hieracium invasion in Marlborough, New Zealand. New Zealand Journal of Ecology 22:121-118.

Rose, A. B., K. H. Platt, and C. M. Frampton. 1995. Vegetation change over 25 years in a New Zealand shorttussock grassland: effects of sheep grazing and exotic invasions. New Zealand Journal of Ecology 19:163-174.

Ruiz, G. M., and J. T. Carlton. 2003. Invasion vectors: a conceptual framework for management. Pages 459-504 in G. M. Ruiz and J. T. Carlton, editors. Invasive species: vectors and management. Island Press, Covolo, California, USA.

Smith, M. D., J. C. Wilcox, T. Kelly, and A. K. Knapp. 2004. Dominance not richness determines invasibility of tallgrass prairie. Oikos 106:253-262.

Spence, L. A., I. A. Dickie, and D. A. Coomes. 2011 a. Arbuscular mycorrhizal inoculum potential: a mechanism promoting positive diversity-invasibility relationships in mountain beech forests in New Zealand? Mycorrhiza 21: 309-314.

Spence, L. A., J. V. Ross, S. K. Wiser, R. B. Allen, and D. A. Coomes. 2011b. Disturbance affects short-term facilitation, but not long-term saturation, of exotic plant invasion in New Zealand forest. Proceedings of the Royal Society B 278:14571466.

Stachowicz, J. J., and J. E. Byrnes. 2006. Species diversity, invasion success, and ecosystem functioning: disentangling the influence of resource competition, facilitation, and extrinsic factors. Marine Ecology Progress Series 311:251252.

Thomas, A., R. B. O'Hara, U. Ligges, and S. Sturtz. 2006. Making BUGS open. R News 6:12-17.

Thomsen, M. A., C. M. D'Antonio, K. B. Suttle, and W. P. Sousa. 2005. Ecological resistance, seed density and their interactions determine patterns of invasion in a California coastal grassland. Ecology Letters 8:160-170.

Tilman, D. 1997. Community invasibility, recruitment limitation, and grassland biodiversity. Ecology 78:81-92.

van der Heijden, M. G. A., R. D. Bardgett, and N. M. v. Straalen. 2008. The unseen majority: soil microbes as drivers of plant diversity and productivity in terrestrial ecosystems. Ecology Letters 11:296-310.

Von Holle, B., and D. Simberloff. 2005. Ecological resistance to biological invasion overwhelmed by propagule pressure. Ecology 86:3212-3218.

Williamson, M. H. 1996. Biological invasions. Chapman and Hall, London, UK.

Wiser, S. K., and R. Allen. 2000. Hieracium lepidulum invasion of indigenous ecosystems. Conservation Advisory Science Notes 278:1-9.

Wiser, S. K., R. B. Allen, P. W. Clinton, and K. H. Platt. 1998. Community structure and forest invasion by an exotic herb over 23 years. Ecology 79:2071-2081.

\section{Supplemental Material}

\section{Appendix}

A table of recruitment function parameter comparisons across habitats and cohorts after four years, a map of the study area in South Island, New Zealand, and a figure showing seedling recruitment and subsequent mortality over time in each of the six habitats (Ecological Archives E095-077-A1). 